\title{
One Half or $50 \%$ ? An Eye-Tracking Study of Number Representation Readability
}

\author{
Luz Rello ${ }^{1,2}$, Susana Bautista ${ }^{3}$, Ricardo Baeza-Yates ${ }^{1,4}$, Pablo Gervás ${ }^{3}$, \\ Raquel Hervás ${ }^{3}$, and Horacio Saggion ${ }^{2}$ \\ ${ }^{1}$ Web Research Group, Universitat Pompeu Fabra, Barcelona \\ ${ }^{2}$ Natural Language Processing Group, Universitat Pompeu Fabra, Barcelona \\ ${ }^{3}$ Natural Interaction based on Language, Universidad Complutense de Madrid \\ ${ }^{4}$ Yahoo! Labs, Barcelona \\ \{luzrello, rbaeza\}@acm.org, \{subautis, raquelhb\}@fdi.ucm.es, \\ pgervas@sip.ucm.es, horacio.saggion@upf.edu
}

\begin{abstract}
Are numbers expressed as digits easier to read and understand than written with letters? What about fractions and percentages? Exact or rounded values? We present an eye-tracking study that attempts to answer these questions for Spanish, using fixation and reading time to measure readability as well as comprehension questions to score understandability. We find that digits are faster to read but do not help comprehension. Fractions help understandability while percentages help readability. No significant results were found concerning the influence of rounding. Our experiments were performed by 72 persons, half of them with dyslexia. To the best of our knowledge, this is the first study that addresses the cognitive load of number representation in any language, even more for people with dyslexia.
\end{abstract}

Keywords: textual accessibility, dyslexia, user testing, eye-tracking, readability, comprehension, number representation.

\section{Introduction}

Worldwide, around $15-20 \%$ of the population has a language-based disability; where $70-80 \%$ of it is likely dyslexic [27]. Some of the these disabilities make more difficult the comprehension of texts written for a generic public. For this reason, United Nations [36] recommend that all public information services and documents should be accessible to the widest possible readership. Given this, there are different initiatives that propose guidelines to help rewriting a text to make it more comprehensive. Some of them are Plain Language ${ }^{1}$ and the European Guidelines for the Production of Easy-to-Read Information [21].

In addition, a large percentage of information expressed in daily news or reports contain numerical expressions (economical statistics, demographic data, etc.), but

\footnotetext{
${ }^{1}$ http: / /www . plainlanguage.gov/

P. Kotzé et al. (Eds.): INTERACT 2013, Part IV, LNCS 8120, pp. 229-245, 2013.

(C) IFIP International Federation for Information Processing 2013
} 
many people have problems understanding complex expressions, including non-native speakers, and people with limited education or some kind of social or cognitive disability, such as dyslexia. Numerical information can have different representations such as: using digits or words, rounded numbers or decimals, fractions instead of percentages, etc. According to cognitive studies, numbers in a text are processed in a different way than words [13], and the presence of numbers in the text impacts the reading process [34].

Dyslexia is a neurological reading disability characterized by difficulties with accurate and/or fluent word recognition and by poor spelling and decoding abilities [50]. Depending on the language, the estimation of the prevalence of dyslexia varies from $10-17.5 \%$ for the population in the U.S.A. [26] to 8.6-11\% for the Spanish speaking population $[8,29,42]$. People with dyslexia find problems to recognize and recollect not only letters but also numbers $[11,37]$. Although dyscalculia ${ }^{2}$ and dyslexia are two different disabilities, they are comorbid $[33]^{3}$ and people with dyslexia are more likely to have Math learning difficulties [32]. For this reason we are particularly interested in studying how the complexity of numerical expressions affects the comprehension of a text.

In this context, the main goal of this paper is to study how number representation impacts text readability and understandability for native Spanish speakers with or without dyslexia. Readability refers to the legibility of a text, that is, the ease with which text can be read, while understandability refers to comprehensibility, the ease with which text can be understood. With this goal in mind, we conducted three experiments with 72 persons (36 with dyslexia) using eye-tracking and comprehension questionnaires. From our results we can quantify the impact of numerical expressions in the reading process for people with or without dyslexia, and it is possible to apply this information to the adaptation of numerical information so texts are more accessible to the widest number of readers.

To the best of our knowledge, this is the first time that numerical representations are measured in terms of readability and comprehension using our methodology. Therefore, this paper presents three main contributions:

- The first analysis of how numerical information impacts text readability and understandability for people with or without dyslexia using a methodology that includes eye-tracking and comprehension questionnaires.

- Numerical information represented as digits improve readability for people with dyslexia.

- Numerical information represented as percentages improve readability for people with dyslexia.

The rest of the paper is organized as follows. Section 2 covers the related work. In Section 3 we present the details of the experimental methodology. Section 4 presents

\footnotetext{
${ }^{2}$ A specific learning disability involving innate difficulty in learning or comprehending arithmetic. It is akin to dyslexia and includes difficulty in understanding numbers, learning how to manipulate numbers, learning mathematical facts, and a number of other related symptoms [7].

${ }^{3}$ Comorbidity indicates a medical condition (in this case dyscalculia) existing simultaneously but independently with another condition (dyslexia).
} 
our results and Section 5 discusses them. Conclusions and future work are drawn in Section 6. Finally, in the Appendix, the data used are presented.

\section{Related Work}

Experimental psychology and cognitive neuropsychology have dealt with the study of number processing and calculation over the last two decades. Many researchers have studied the cognitive processes that are responsible for number processing and calculation, with the goal of contributing to the improvement of teaching and learning processes. For example, $[24,46]$ present findings about how the frequency of use of a word or number is an influential variable in the reading process. In addition, it seems that numerical expressions most frequently used require less time for recognition.

Researchers in psychophysics [39] have also studied various aspects of reading: impact of text context on readability and eye movements during reading, among others. When numerical expressions are expressed in digits there is a faster access to its semantic representation than when expressed in words [12, 18, 19, 28].

From experimental psychology there is evidence regarding the importance of the frequency of use of numerical expressions. For example, Brysbaert [6] investigated number processing by looking at reading time using eye-tracking and showing that subjects have longer eye fixations with more frequently used numbers.

Overall, it is a generally accepted hypothesis that the probability of making a fixation on a particular linguistic unit is determined by the perceptual or informational relevance of the unit, and the degree of difficulty of processing required for its identification. Due to the quantitative nature of this measure, it is not easy to unravel what are the specific reasons justifying the preference for fixations on certain kinds of linguistic units. Thus, the visual processing of words has been shown to be affected significantly by factors such as length, frequency, type of vocabulary, predictability, or word ambiguity [40].

There is an extensive body of knowledge that takes into consideration eye movements of readers with dyslexia using eye-tracking. While some found differences among people with or without dyslexia [16], others did not [48]. Hyönä et al. [25] studies the effect of word length and word frequency in relation with eye fixation patterns. Their results show that low frequency and long words present longer gaze durations and more re-inspections although in [43] only more frequent words presented significantly shorter fixation durations. However, we found no previous work that investigates numerical representations in readers with dyslexia using eyetracking, nor for people in general. In fact, it is the first user evaluation of numerical representations.

Currently there is plenty of automatic text simplification research based on cognitive aspects. The main objectives are to identify simplification operations that can be applied to adapt a text using some kind of automatic means. Most of the text simplification approaches disregard the treatment of numerical expressions [5, 9] except from [4] that is a numerical expressions simplification system designed on the basis of corpus analyses $[2,15]$. However, to the extent of our knowledge there are no user 
evaluations regarding the impact of simplifying numerical expressions as the one we present in this paper.

\section{Methodology}

We designed three different experiments to study the effect of different representations of numerical expressions with respect to readability and understandability. In the experiments, 72 participants (36 with dyslexia) had to read several texts in Spanish with different representations of numerical expressions. We tested the following hypotheses:

- H1.1: Readability will increase if digits are used instead of words for representing numerical expressions.

- H1.2: Understandability will increase if digits are used instead of words for representing numerical expressions.

- H2.1: Readability will increase if rounded numerical expressions are used instead of unrounded expressions (with decimals).

- H2.2: Understandability will increase if rounded numerical expressions are used instead of unrounded expressions (with decimals).

- H3.1: Readability will increase if numerical expressions are expressed in percentages instead of fractions.

- H3.2: Understandability will increase if numerical expressions are expressed in percentages instead of fractions.

\subsection{Design}

In the first experiment, Digits vs. Words, the independent variable [ \pm digits] had two levels: [+digit] denotes the condition where numbers in the text were written in digits, i.e. 22, and [-digit] denotes the condition where numbers were written using words, i.e. veintidos ('twenty two').

In the second experiment, Rounding vs. Decimals, the independent variable [ \pm round] had again two levels: [+round] denotes the condition where numbers were rounded, without decimals i.e. 19 and [-round] denotes the condition where numbers in the text were written with decimals i.e. 19.45.

In the third experiment, Percentages vs. Fractions, the independent variable [ \pm percentage] also had two levels: [+percentage] denotes the condition where numbers in the text were written using percentages, i.e. $25 \%$ and [-percentage] denotes the condition where numbers in the text were written using fractions i.e. 1/4.

The experiment followed a within-subjects design, so every participant contributed to each of the conditions in the experiments. The order of conditions was counterbalanced to cancel out sequence effects. To measure understandability and readability, we measured fixation duration and the correct answers from the questionnaires, respectively. Sometimes both terms, readability and understandability, have been used interchangeably. However, previous research with people with dyslexia has 
shown that both concepts need to be taken into consideration separately. For instance, in [41] comprehension has been found to be independent of readability for people with dyslexia, while text readability can be used as an indicator of comprehension for people without dyslexia. Therefore, in this study we distinguish between readability and understandability.

Fixation Duration. When reading a text, the eye does not move contiguously over the text, but alternates saccades and visual fixations, i.e. jumps in short steps and rests on parts of the text. Fixation duration denotes how long the eye rests still on a single place of the text. Fixation duration has been shown to be a valid indicator of readability. According to [30, 40, 47], shorter fixations are associated with better readability while longer fixations can indicate that processing loads are greater. Hence, we use fixation duration across the whole text as measure to quantify readability.

Correct Answers. To measure text comprehension we used questionnaires, one per text. We used multiple-choice questions with three possible choices, one correct and two incorrect. From these answers, we computed the percentage of correct answers, where the correct choice scored $100 \%$ and the others $0 \%$.

\subsection{Participants}

Seventy-two Spanish native speakers undertook the experiments, 36 without dyslexia (group $\mathrm{N}$ ) and 36 with dyslexia (group D). Their ages ranged from 16 to 50, with a mean age of 26.94 for group $\mathrm{N}$ and 23.38 for group $\mathrm{D}$. All the participants were asked to bring their dyslexia diagnosis to the experiment. Except from 3 participants with dyslexia and 2 without who had no higher education, the rest were attending school or high school (17 participants with dyslexia and 13 participants without dyslexia) or were studying or had already finished university degrees (16 participants with dyslexia and 21 participants without dyslexia).

\subsection{Materials}

To study the effects of numerical expressions we need to study target numerical expressions in context, i.e. as part of a text. To isolate the effects of these variables, the texts need to be comparable in complexity. In this section, we describe how we designed the texts and the target numerical expressions that were used in this study.

Base Texts. As basis for our manipulations, we created six texts with an average length of 62.33 words. To meet the comparability requirements among the texts belonging to the same experiment, we took into account the parameters that different complexity measures take into consideration [14]. Next, we present the characteristics shared by the texts in each experiment:

(a) They have the same number of target words: Seven [ \pm digits] numerical expressions pairs for each of the texts in Digits vs. Words, seven [ \pm round] expressions pairs for each of the texts in Rounding vs. Decimals, and four [ \pm percentages] target numerical expressions in Percentages vs. Fractions. 
(b) They share the same genre and are about similar topics: fast food ingredients.

(c) They contain the same number of sentences: three sentences in Percentages vs. Fractions and four sentences in the other two experiments.

(d) The base texts of each experiment have the same number of words per text (39 words in Percentages vs. Fractions and 63 words for the other two experiments).

(e) All the texts have a similar word length average ranging from 4.88 to 5.24 letters.

(f) They do not contain named entities, foreign words, or numerical acronyms.

The presentation of the text has an effect on reading speed so we used the same layout for all the texts. We chose a recommended font type for reading in a screen, sans serif arial, a large size (20 points) and 62 characters/column and unjustified text and recommended color and brightness contrast using a black font with crème background $[1,45]^{4}$

Target Numerical Expressions. For the numerical expressions we used the following criteria:

(a) We chose pairs of numerical expressions denoting the same number because the frequency of the number expressed has an impact on its processing time [24, 46]. Therefore the same numerical expressions with different representation were chosen for the three experiments.

(b) We did not include ambiguous numerical expressions because they require more processing than unambiguous ones [40]. For instance, depending on the context cien ('hundred') could also mean "very fast" in Spanish i.e. Estoy trabajando a cien ('I am working very fast') and Las manzanas están a cien ('The apples cost one hundred').

(c) We did not used orthographically similar numerical expressions, (i.e. mirror numbers ' 6 ' and ' 9 ') in the same text since such representations can be a major difficulty for people with dyslexia [17].

(d) In the experiment Digits vs. Words, we selected different numerical expressions, i.e., with decimals, rounded, two or three digits and percentages (see the Appendix for the data used).

(e) In the experiment Rounding vs. Decimals, we rounded the original numbers, always using modifiers when there was a loss of precision, i.e. un poco ('a little'), casi ('almost').

(f) In the experiment Percentages vs. Fractions, we selected frequently occurring percentages and their corresponding fractions

Comprehension Questionnaires. Each questionnaire is composed by two items, one inferential question i.e. to be answered correctly the question requires a deep understanding of the content of the text) and one question about details of the text which were expressed using a numerical expression. For each text there were two comprehension questions. The first was about the overall content of the text and the second was about the numerical part of the text. The later question always was phrased with

4 The CYMK are crème (FAFAC8) and black (000000). Color difference: 700, Brightness difference: 244 [45]. 
the same number representation that was used in the text. Two examples, an inferential question (i) and a question devoted to details (ii) are given in Figure 1.

(i) El texto trata sobre: ('The text is about':)

(a) La descomposición de una hamburguesa. ('The decomposition of a burger.')

(b) La creación de una hamburguesa. ('The creation of a burger.')

(c) La composición de una hamburguesa. ('The composition of a hamburger'.) (ii) Una porción de patatas fritas tiene un máximo de: ('One portion of french fries has a maximum of':)

(a) 200 kilocalorías. ('200 kilocalories.')

(b) 300 kilocalorías. ('300 kilocalories.')

(c) 400 kilocalorías. ('400 kilocalories'.)

Fig. 1. Two examples of questions in the comprehension tests

Preference Questionnaires. Each participant performed a questionnaire with 20 questions that were rated using a 5 level Likert scale. For 10 of the statements the participant was asked about how easy was to read the text, that is, readability, while for the other 10 statements the participant was asked about how easy was to comprehend the text, that is, understandability. Each of the statements contained a numerical expression, using one of the following representations: rounded, unrounded, percentage and fractions, where 8 were written in words and 12 in digits. In the Appendix we present the set of numerical expressions used.

\subsection{Equipment}

The eye tracker used was the Tobii T50 [49] that has a 17-inch TFT monitor with a resolution of $1024 \times 768$ pixels. The eye tracker was calibrated for each participant and the light focus was always in the same position. The distance between the participant and the eye tracker was constant (approximately $60 \mathrm{~cm}$. or 24 in.) and controlled by using a fixed chair.

\subsection{Procedure}

The sessions were conducted at Universitat Pompeu Fabra and they lasted from 20 to 30 minutes, depending on the participant. In each session, the participant was alone with the interviewer in the quiet room prepared for the study, performing the following three steps.

First, we began with a questionnaire designed to collect demographic information. Second, we conducted the experiments that were recorded using eye-tracking. Out of the 72 participants, 40 participated in the experiment Digits vs. Words $(20 \mathrm{D}, 20 \mathrm{~N})$ and 32 carried out the Rounding vs. Decimals experiment (16 D, 16 N). Finally, The experiment Percentages vs. Fractions was carried out by 32 participants (16 D, 16 N) who had already participated in either the first or the second experiment, were not 
tired of reading, and were willing to read more. The participant was asked to read the texts in silence and to complete the comprehension tests. Third, we carried out a user preferences survey.

\section{Results}

In this section we present the analysis of the results of the eye-tracking and comprehension tests. The measures used for the comparison of the text passages were the means of the fixation duration, the total duration of reading, and the correct answers. In order to test our hypotheses, differences between groups and conditions were tested by means of (Bonferroni-corrected) Student's t-tests.

Shorter fixations are preferred to longer ones because faster reading is related to more readable texts [51]. We compare readability with understandability through the inferential items of the comprehension questionnaires.

First, we study the differences between both groups. Then, we analyze the impact of the different numerical expressions in readability and understandability.

\subsection{Digits vs. Words}

We did not find statistical significance in readability $(p<0.444)$ for group $\mathrm{N}$ (see Table 1). However, we found statistical significance for readability in group D taking into account the mean of fixation time $(p<0.054)$. This result supports our H1.1 hypothesis.

No statistical significance was found for both groups. Hence we reject hypothesis H1.2 ( $p<0.241$ for group $\mathrm{N}$ and $p<0.269$ for group D).

\subsection{Rounding vs. Decimals}

We reject hypothesis $\mathrm{H} 2.1$, since we did not find statistical significance in readability in group $\mathrm{N}(p<0.867)$ nor in group $\mathrm{D}(p<0.685)$ when reading texts with rounded numerical expressions taking into account the mean of fixation time (see Table 2).

We also refute $\mathrm{H} 2.2$ because we did not found statistical significance for understandability in both groups ( $p<0.310$ in group $\mathrm{N}$ and $p<0.695$ in group $\mathrm{D})$.

Table 1. Experimental results for Digits vs. Words

\begin{tabular}{|l||c|c|}
\hline \multirow{2}{*}{$\begin{array}{c}\text { Measure } \\
\text { (ave. } \pm \text { std.dev.) }\end{array}$} & \multicolumn{2}{|c|}{ Group N } \\
\cline { 2 - 3 } Fixations Duration & $0.19 \pm 0.03$ & $0.19 \pm 0.02$ \\
Correct Answers & $87.50 \%$ & $95.00 \%$ \\
\hline \hline \multirow{2}{*}{ Fixations Duration } & \multicolumn{3}{|c|}{ Group D } \\
\cline { 2 - 3 } Correct Answers & $0.21 \pm 0.04$ & $0.24 \pm 0.05$ \\
& $85.35 \%$ & $76.51 \%$ \\
\hline
\end{tabular}


Table 2. Experimental results for Rounding vs. Decimals

\begin{tabular}{|l||c|c|}
\hline \multirow{2}{*}{$\begin{array}{c}\text { Measure } \\
\text { (ave. } \pm \text { std.dev.) }\end{array}$} & \multicolumn{2}{|c|}{ Group N } \\
\cline { 2 - 3 } Fixations Duration & $0.19 \pm 0.03$ & $0.19 \pm 0.03$ \\
Correct Answers & $97.22 \%$ & $90.87 \%$ \\
\hline \hline & \multicolumn{2}{|c|}{ Group D } \\
\cline { 2 - 3 } Fixations Duration & $0.23 \pm 0.04$ & $0.22 \pm 0.04$ \\
Correct Answers & $90.63 \%$ & $91.67 \%$ \\
\hline
\end{tabular}

Table 3. Experimental results for Percentages vs. Fractions

\begin{tabular}{|l||c|c|}
\hline \multirow{2}{*}{$\begin{array}{c}\text { Measure } \\
\text { (ave. } \pm \text { std.dev.) }\end{array}$} & \multicolumn{2}{|c|}{ Group N } \\
\cline { 2 - 3 } Fixations Duration & $0.19 \pm 0.03$ & $0.18 \pm 0.03$ \\
Correct Answers & $88.19 \%$ & $96.86 \%$ \\
\hline \hline \multirow{2}{*}{ Fixations Duration } & \multicolumn{2}{|c|}{ Group D } \\
\cline { 2 - 3 } Correct Answers & $0.20 \pm 0.06$ & $0.23 \pm 0.05$ \\
& $80.55 \%$ & $88.89 \%$ \\
\hline
\end{tabular}

\subsection{Percentages vs. Fractions}

We did not find statistical significance in readability for group $\mathrm{N}(p<0.462)$ taking into account the mean of fixation time (see Table 3 ). However, our results confirm H3.1 because we found statistical significance for readability in group D $(p<0.046)$ when reading texts with numerical expressions in percentages. This group reads faster texts with expressions in percentages than texts with numerical information in fractions.

On the other hand, we reject $\mathrm{H} 3.2$ because we did not found statistical significance results for understandability in both groups $(p<0.170$ for group $\mathrm{N}$ and $p<0.474$ for group D, see again Table 3.

\subsection{Survey}

We found a high Pearson correlation of 0.95 between the answers of both groups. Therefore, groups $\mathrm{N}$ and D generally agreed in their answers with respect to readability and understandability. In Figure 2 we show the histograms of the survey results. Then, we calculated the standard deviation for all the statements. For the readability answers the standard deviation was significantly higher in group D $(\mu=1.20$ seconds, $s=0.41)$ than in group $\mathrm{N}(\mu=0.87$ seconds, $s=0.46)$, with $p=0.007$. This means that participants with dyslexia had a higher variability in their ratings. For the understandability answers, we found no significant difference between groups in their standard deviation ( $p=0.157)$ for group D $(\mu=1.04$ seconds, $s=0.44)$ and for group $\mathrm{N}$ ( $\mu=0.89$ seconds, $s=0.37$ ). 


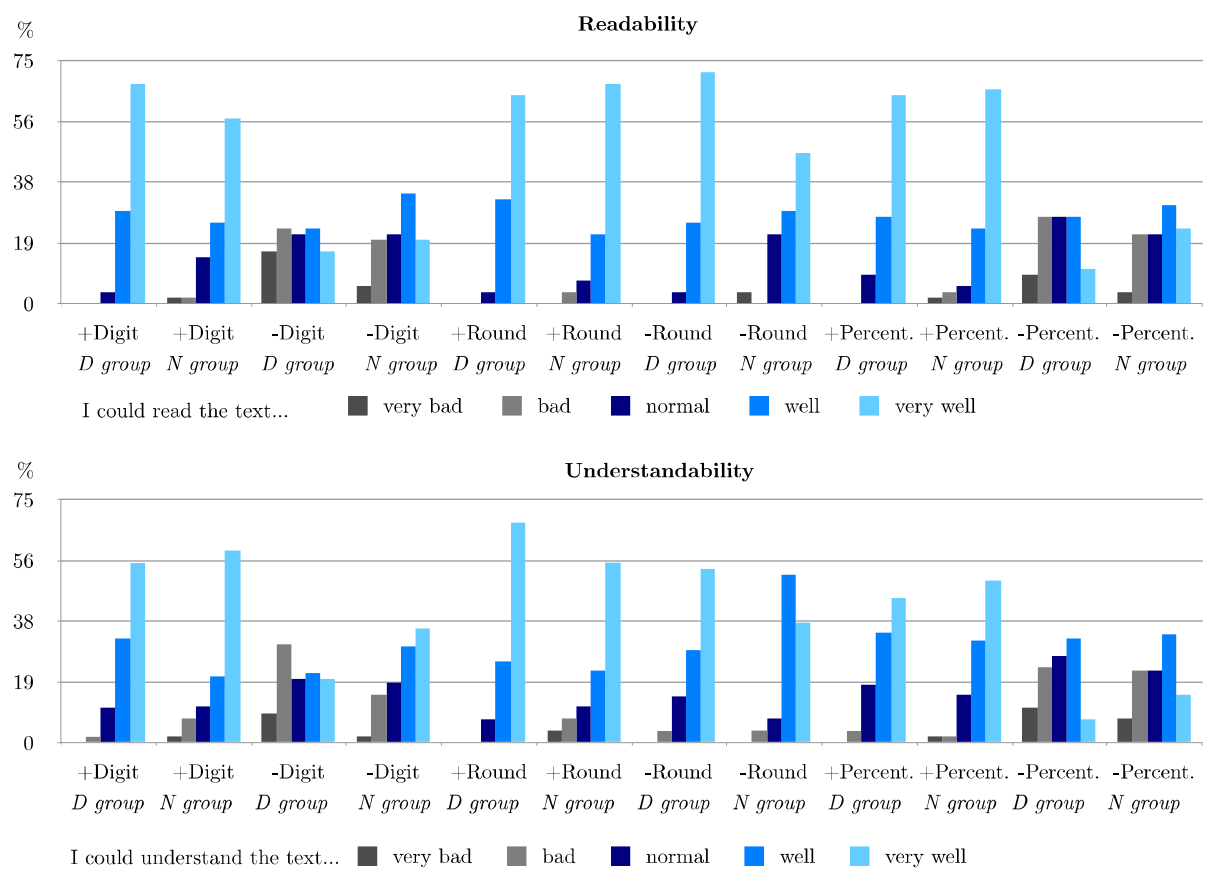

Fig. 2. Survey results for readability and understandability

Digits vs. Words. Participants significantly found numbers written in digits more readable than in letters $(p<0.001)$ as well as more understandable $(p<0.001)$. We also found significance within groups for readability $(p<0.001$ in group D and $p<$ 0.001 in group $\mathrm{N}$ ) and understandability $(p<0.001$ in group $\mathrm{D}$ and $p=0.014$ in group $\mathrm{N})$.

Rounding vs. Decimals. We did not find statistical significance for readability between rounded and unrounded numbers $(p=0.272)$ nor for understandability $(p=$ $0.446)$. No significant differences were found within groups for readability $(t(53.937)$ $=0.479, p=0.634$ in group $\mathrm{D}$ and $p=0.111$ in group $\mathrm{N}$ ) and understandability $(p=$ 0.163 in group $\mathrm{D}$ and $p=0.888$ in group $\mathrm{N}$ ).

Percentages vs. Fractions. Participants significantly found percentages more readable than fractions $(p<0.001)$ as well as more understandable $(p<0.001)$. We also found significance within groups for readability $(p<0.001$ in group $\mathrm{D}$ and $p<0.001$ in group $\mathrm{N}$ ) and understandability $(p<0.001$ in group $\mathrm{D}$ and $p<0.001$ in group $\mathrm{N})$.

\section{Discussion}

With respect to differences between the use of digits and the use of numerical expressions in words, results indicate a statistically significant improvement in performance 
for readability in people with dyslexia when digits are employed. In contrast, in group $\mathrm{N}$, we found no significant differences. This agrees with the fact that numerical expressions described using words require a longer number of words and/or characters in comparison with the corresponding versions using digits. Overall length is an already known parameter that creates difficulties for people with dyslexia, so the reduction in length involved in phrasing a number in digits should make it easier to read for them. Results for understandability in experiment digits vs. words are not statistically significant for both groups.

With respect to differences between the use of rounded and unrounded numbers, none of the differences found are statistically significant. Rounding numbers even with modifiers such as "around" or "almost" did not have the expected effect in our experiments.

With respect to differences between the use of percentages and fractions, there is a statistically significant increase in readability for group D when percentages are used instead of fractions. In contrast, no differences were found for group N. Again, results for understandability are not statistically significant in either case. There is an apparent contradiction in that for group D percentages seem to be easier to read but more difficult to understand. A possible explanation might be related to the nature of these expressions. From a conceptual point of view, both percentages and fractions convey the relative proportion between two quantities: the value of the percentage and 100 in the case of percentages, and the value of the numerator and the value of the denominator in fractions. However, the reference value in the case of percentages is implicit (or conveyed by the \% sign). This implies that for fractions, two quantities have to be read, whereas only one needs to be read for percentages. This may account for the comparative ease for group D of reading percentages (only one quantity to read) vs. fractions (two different quantities to read). Participants that took this experiment did it because they were not tired and still willing to read more. In most cases participants with dyslexia were adults, and as such they have reading skills that are similar to adults without dyslexia. Note that fixation duration for these participants is shorter when reading percentages. More over, the percentages used in the texts were the most commonly used (see Appendix) and the more frequent the word, the shorter the eye fixation [25].

The standard deviations of the survey reveal that people with dyslexia made a greater difference between readability and understandability than people without dyslexia. For people without dyslexia, easier reading was correlated to text comprehension while participants with dyslexia dissociated these two elements, perhaps due do the nature of dyslexia, which affects reading but not comprehension of the language.

The higher variability of scores indicates that for people with dyslexia the representation of numbers has a much bigger impact on readability. However, the correlation of the answers of people with or without dyslexia is high. Hence, both groups generally agree in their rates with respect to readability and understandability.

The significant difference in the number representations of the survey for Digits vs. Words and Percentages vs. Fractions, are consistent with the quantitative data from the eye tracker where we found significant variations. Hence, the performance and the preferences of our participants with respect to these number representations are consistent. 


\section{Conclusions and Future Work}

The presence of numerical information in a text impacts its readability. We have analyzed some of the different representations of numerical expressions in text to study their influence in the reading process of people with or without dyslexia. For each experiment our hypotheses have been tested and depending on the kind of numerical information for each group we have obtained different results.

The main contribution of this research is that numbers represented as digits instead of words as well as percentages instead of fractions improve readability of people with dyslexia.

These results may prove to be of value in providing empirical basis for the development or refinement of guidelines for the simplification of text. These guidelines exist in very general form [21] and they are currently employed as reference in a number of efforts to improve accessibility of text for groups of users with special needs. An empirical grounding that correlates particular expressions with particular user groups would be a very positive contribution.

This work can motivate work on text simplification for textual accessibility regarding numerical expressions [3, 4, 38]. Also, these findings can have an impact on current interactive systems for people with dyslexia that modify the text presentation but not its content such as Claro ScreenRuler Suite [10], SeeWord [22] or IDEAL e-Book reader [31]. We plan to integrate these findings in DysWebxia 2.0 [44], a tool that modifies text content and layout for people with dyslexia.

Another field in which these results can be expected to have an impact is that of the assessment of readability. In general terms, computational models for predicting readability of texts are used, like FOG [23], Flesch, Flesch-Kincaid [20], and SMOG [35]. Current efforts along this line are considering a number of factors like average number of characters per word and average syllables per word to predict a readability score, but include no specific account for numerical expressions. Based on the results presented here, an effort might be made to expand the set of features used in the assessment of readability to include numerical expressions.

Future work includes the evaluation of numerical representation of other target groups and other measures of readability. We also need to evaluate other representations for specific numerical expressions, for example to represent time.

Acknowledgments. We thank Mari-Carmen Marcos for her assistance with the eyetracker hardware, Martin Pielot for his help with statistics, and Jerónimo Bautista Velázquez for his help in distributing our experiments announcement among experts. The research of the first author was funded by the Spanish Ministry of Education and Science (Grant TIN2009-14560-C03-01) and the Catalonian FI scholarship program while the research of the second, fourth and fifth authors was funded by the Spanish Ministry of Education and Science (Grant TIN2009-14659-C03-01 Project), Universidad Complutense de Madrid and Banco Santander Central Hispano (GR58/08 Research Group Grant). 


\section{References}

1. Al-Wabil, A., Zaphiris, P., Wilson, S.: Web navigation for individuals with dyslexia: An exploratory study. In: Stephanidis, C. (ed.) Universal Access in HCI, Part I, HCII 2007. LNCS, vol. 4554, pp. 593-602. Springer, Heidelberg (2007)

2. Bautista, S., Drndarevic, B., Hervás, R., Saggion, H., Gervás, P.: Análisis de la Simplificación de Expresiones Numéricas en Español mediante un Estudio Empírico (Analysis of the Simplification of Numerical Expressions in Spanish through an Empirical Study). Linguamatica 4(2), 27-41 (2012)

3. Bautista, S., Hervás, R., Gervás, P., Power, R., Williams, S.: How to Make Numerical Information Accessible: Experimental Identification of Simplification Strategies. In: Campos, P., Graham, N., Jorge, J., Nunes, N., Palanque, P., Winckler, M. (eds.) INTERACT 2011, Part I. LNCS, vol. 6946, pp. 57-64. Springer, Heidelberg (2011)

4. Bautista, S., Hervás, R., Gervás, P., Power, R., Williams, S.: A system for the simplification of numerical expressions at different levels of understandability. In: NAACL Workshop Natural Language Processing for Improving Textual Accessibility, NLP4ITA (2013)

5. Bott, S., Rello, L., Drndarevic, B., Saggion, H.: Can Spanish be simpler? LexSiS: Lexical simplification for Spanish. In: Proc. Coling 2012, Mumbay, India (December 2012)

6. Brysbaert, M.: Arabic number reading: On the nature of the numerical scale and the origin of phonological recoding. Journal of Experimental Psychology: General 124(4), 434-452 (1995)

7. Butterworth, B.: Foundational numerical capacities and the origins of dyscalculia. Trends in Cognitive Sciences 14(12), 534-541 (2010)

8. Carrillo, M.S., Alegría, J., Miranda, P., Pérez, S.: Evaluación de la dislexia en la escuela primaria: Prevalencia en español (Evaluation of dyslexia in primary school: The prevalence in Spanish). Escritos de Psicología 4(2), 35-44 (2011)

9. Carroll, J., Minnen, G., Canning, Y., Devlin, S., Tait, J.: Practical simplification of English newspaper text to assist aphasic readers. In: AAAI 1998 Workshop on Integrating Artificial Intelligence and Assistive Technology, Wisconsin (1998)

10. Clarosoftware (2012), http: / / www. clarosoftware.com/index.php?cPath $=348$

11. Cohen, L., Dehaene, S., Verstichel, P.: Number words and number non-words: A case of deep dyslexia extending to Arabic numerals. Brain 117, 267-279 (1994)

12. Damian, M.: Asymmetries in the processing of Arabic digits and number words. Memory \& Cognition 32, 164-171 (2004)

13. Dehaene, S.: Varieties of numerical abilities. Cognition 44, 1-42 (1992)

14. Drndarevic, B., Saggion, H.: Towards automatic lexical simplification in Spanish: an empirical study. In: Proceedings of the NAACL HLT 2012 Workshop Predicting and Improving Text Readability for Target Reader Populations, PITR 2012 (2012)

15. Drndarević, B., Štajner, S., Bott, S., Bautista, S., Saggion, H.: Automatic text simplification in spanish: A comparative evaluation of complementing modules. In: Gelbukh, A. (ed.) CICLing 2013, Part II. LNCS, vol. 7817, pp. 488-500. Springer, Heidelberg (2013)

16. Eden, G., Stein, J., Wood, H., Wood, F.: Differences in eye movements and reading problems in dyslexic and normal children. Vision Research 34(10), 1345-1358 (1994)

17. Ellis, A.: Reading, writing and dyslexia. Erlbaum, London (1984)

18. Fias, W.: Two routes for the processing of verbal numbers: Evidence from the snarc effect. Psychological Research 65, 250-259 (2001) 
19. Fias, W., Brysbaert, M., Geypens, F., d'Ydewalle, G.: The importance of magnitude information in numerical processing: Evidence from the snarc effect. Mathematical Cognition 2, 95-110 (1996)

20. Flesch, R.: A new readability yardstick. Journal of Applied Psychology 32, 221-233 (1948)

21. Freyhoff, G., Hess, G., Kerr, L., Menzel, E., Tronbacke, B., Veken, K.V.D.: European guidelines for the production of easy-to-read information for people with learning disability. Technical Report ISLMH, European Union (1998)

22. Gregor, P., Dickinson, A., Macaffer, A., Andreasen, P.: Seeword: a personal word processing environment for dyslexic computer users. British Journal of Educational Technology 34(3), 341-355 (2003)

23. Gunning, R.: The technique of clear writing. McGraw-Hill (1952)

24. Herrera, A., Macizo, P.: Cómo leemos los números? (How we read numbers?). Ciencia Cognitiva 6(2), 44-47 (2012)

25. Hyönä, J., Olson, R.: Eye fixation patterns among dyslexic and normal readers: Effects of word length and word frequency. Journal of Experimental Psychology: Learning, Memory, and Cognition 21(6), 1430 (1995)

26. Interagency Commission on Learning Disabilities. Learning Disabilities: A Report to the U.S. Congress. Government Printing Office, Washington, DC, U.S. (1987)

27. International Dyslexia Association. Definition of dyslexia. Based in the initial definition of the Research Committee of the Orton Dyslexia Society, former name of the IDA, done in 1994 (2011), http: / / interdys .org/DyslexiaDefinition.htm

28. Ito, Y., Hatta, T.: Semantic processing of Arabic, Kanji and Kana numbers: Evidence from interference in physical and numerical size judgments. Memory \& Cognition 31, 360-368 (2003)

29. Jiménez, J.E., Guzmán, R., Rodríguez, C., Artiles, C.: Prevalencia de las dificultades específicas de aprendizaje: La dislexia en español (the prevalence of specific learning difficulties: Dyslexia in Spanish). Anales de Psicología 25(1), 78-85 (2009)

30. Just, M., Carpenter, P.: A theory of reading: From eye fixations to comprehension. Psychological Review 87, 329-354 (1980)

31. Kanvinde, G., Rello, L., Baeza-Yates, R.: IDEAL: a dyslexic-friendly e-book reader (poster). In: Proc. ASSETS 2012, Boulder, USA. ACM Press (October 2012)

32. Landerl, K., Bevan, A., Butterworth, B., et al.: Developmental dyscalculia and basic numerical capacities: A study of 8-9-year-old students. Cognition 93(2), 99-125 (2004)

33. Landerl, K., Fussenegger, B., Moll, K., Willburger, E., et al.: Dyslexia and dyscalculia: two learning disorders with different cognitive profiles. Journal of Experimental Child Psychology 103(3), 309 (2009)

34. McCloskey, M., Caramazza, A., Basili, A.: Cognitive mechanisms in number processing and calculation: Evidence from dyscalculia. Brian and Cognition 4, 171-196 (1985)

35. McLaughlin, G.H.: Smog grading: A new readability formula. Journal of Reading 12(8), 639-646 (1969)

36. U. Nations. Standard Rules on the Equalization of Opportunities for Persons with Disabilities. Technical report, United Nations (1994)

37. Newell, A., Booth, L.: The use of lexical and spelling aids with dyslexics. Computers and Literacy, 35-44 (1991)

38. Power, R., Williams, S.: Generating numerical approximations. Computational Linguistics 38(1) (2012)

39. Rayner, K.: Eye movements in reading and information processing: 20 years of research. Psychological Bulletin 124, 372-422 (1998) 
40. Rayner, K., Duffy, S.: Lexical complexity and fixation times in reading: Effects of word frequency, verb complexity, and lexical ambiguity. Memory \& Cognition 14(3), 191-201 (1986)

41. Rello, L., Baeza-Yates, R.: Lexical quality as a proxy for web text understandability (poster). In: The 21st International World Wide Web Conference (WWW 2012), Lyon, France (April 2012)

42. Rello, L., Baeza-Yates, R.: The presence of English and Spanish dyslexia in the Web. New Review of Hypermedia and Multimedia 8, 131-158 (2012)

43. Rello, L., Baeza-Yates, R., Dempere-Marco, L., Saggion, H.: Frequent words improve readability and short words improve understandability for people with dyslexia. In: Kotzé, P., Marsden, G., Lindgaard, G., Wesson, J., Winckler, M. (eds.) INTERACT 2013, Part IV. LNCS, vol. 8120, pp. 203-219. Springer, Heidelberg (2013)

44. Rello, L., Baeza-Yates, R., Saggion, H., Bott, S., Carlini, R., Bayarri, C., Gòrriz, A., Gupta, S., Kanvinde, G., Topac, V.: Dyswebxia 2.0!: Accessible text for people with dyslexia (demo). In: Proc. W4A 2013, The Paciello Group Web Accessibility Challenge, Rio de Janeiro, Brazil (2013)

45. Rello, L., Kanvinde, G., Baeza-Yates, R.: Layout guidelines for web text and a web service to improve accessibility for dyslexics. In: International Cross Disciplinary Conference on Web Accessibility (W4A 2014), Lyon, France. ACM Press (April 2012)

46. Salguero, M., Alameda, J.: El procesamiento de los números y sus implicaciones educativas (Number processing and its educational implications). XXI Revista de Educación (Education Journal) 5, 181-189 (2003)

47. Sereno, S., Rayner, K.: Measuring word recognition in reading: eye movements and eventrelated potentials. Trends in Cognitive Sciences 7(11), 489-493 (2003)

48. Stanley, G., Smith, G., Howell, E.: Eye-movements and sequential tracking in dyslexic and control children. British Journal of Psychology 74(2), 181-187 (1983)

49. Tobii Technology. Product description Tobii 50 Series (2005)

50. Vellutino, F., Fletcher, J., Snowling, M., Scanlon, D.: Specific reading disability (dyslexia): What have we learned in the past four decades? Journal of Child Psychology and Psychiatry $45(1), 2-40$ (2004)

51. Williams, S., Reiter, E., Osman, L.: Experiments with discourse-level choices and readability. In: Proceedings of the 9th European Workshop on Natural Language Generation (ENLG 2003), Budapest, Hungary (2003)

\section{Appendix: Synonyms Pairs}

Experiment 1: Digits vs. Words and Experiment 2: Rounding vs. Decimals (the set of target numerical expression used for each experiment are written in brackets, that is, [Digits / Words - Decimals / Rounding]).

Composición de una hamburguesa: El pan supone entre el [30\% / treinta por ciento - $18,53 \%$ / casi el $20 \%$ ] y el [50\% / cincuenta por ciento - $29,57 \%$ / casi el $30 \%$ ] del peso de una hamburguesa. La hamburguesa tiene un valor energético que oscila entre las [250 / doscientas cincuenta - 297 / casi 300] y [300 / trescientas 398 / casi 400] kilocalorías. Un adulto con actividad moderada necesita en torno a [2.500 / dos mil quinientas - 2.489 / unas 2.500] kilocalorías diarias, por lo que una hamburguesa a la semana no desequilibra ninguna dieta ni siquiera incorporándole 
un sobre de [11 / once - 11,8 / casi 12] gramos de ketchup, que contiene [70 / setenta - 70,8 / un poco más de 70] kilocalorías.

Composition of a burger: The bread is between [30\% / thirty percent $-18.53 \%$ / almost 20\%] and [50\% / fifty percent - 29.57\% / almost 30\%] of the weight of a hamburger. The burger has an energy value of between [ $250 /$ two hundred fifty 297 / almost 300] and [300 / three hundred - 398 / almost 400] kilocalories. A moderately active adult needs about [2,500 / two thousand five hundred - 2,489 / around 2.500] kilocalories a day, so a burger a week not even unbalanced diet incorporating any one of [11 / eleven - 11.8 / almost 12] grams of ketchup, which contains [70 / seventy -70.8 / a little more than 70 ] calories.

Composición de las patatas fritas: Las patatas fritas, a pesar de tener $[3,6 /$ tres coma seis - 3,67 / casi 4] gramos de grasa y [234 / doscientas treinta y cuatro - 214 / un poco más de 200] kilocalorías por cada [100 / cien - 89 / casi 100] gramos, son un alimento muy energético por lo que ha de consumirse en pequeñas cantidades y esporádicamente. Contienen [11 / once - 11,82 / un poco más de 10] gramos de hidratos de carbono con un índice glucémico de [70 / setenta - 68,67 / casi 70]. Es decir, suponen un [50\% / cincuenta por ciento - 58\% / casi un $60 \%$ ] del consumo diario recomendado de hidratos en mujeres y el [30\% / treinta por ciento - 29,12\% / casi un 30\%] en hombres.

Composition of french fries: French fries, despite having [3.6 / three point six 3.67 / almost 4] grams of fat and [234 / two hundred thirty-four - 214 / a little more than 200] kilocalories per [100 / hundred - 89 / almost 100] grams, are a very energetic food which has to be consumed in small quantities and sporadically. Containing [ 11 / eleven - 11.82 / a little more than 10] grams of carbohydrates with a glycemic index of [70 / seventy - 68.67 / almost 70] That is, suppose [50\% / fifty percent $-58 \%$ / almost $60 \%$ ] of the recommended daily intake of carbohydrates in women and $[30 \%$ / thirty percent $-29.12 \%$ / almost $30 \%]$ in men.

\section{Experiment 3: Percentages vs. Fractions}

Composición de una hamburguesa: El pan supone entre el [25\% / 1/4] y el [50\% / 1/2] del peso de una hamburguesa incluyendo el [75\% / 3/4] de los hidratos de carbono de esta. Estos hidratos suponen el [20\% / 1/5] del consumo diario recomendado para un adulto con actividad moderada.

Composition of a burger: The bread is between [25\% / 1/4] and [50\% / 1/2] by weight of a hamburger including [75\% / 3/4] of this carbohydrate. These hydrates represent $[20 \% / 1 / 5]$ of the recommended daily intake for an adult with moderate activity.

Composición de las patatas fritas: Alrededor del [50\% / 1/2] de los componentes de las patatas fritas son hidratos de carbono con un índice glucémico del $[75 \%$ / 
3/4]. Es decir, suponen un [25\% / 1/4] del consumo diario recomendado de hidratos en mujeres y el [20\% / 1/5] en hombres.

Composition of French fries: Approximately [50\% / 1/2] of the components of French fries are carbohydrates with a low glycemic index of [75\% / 3/4]. That is, suppose $[25 \% / 1 / 4]$ of the recommended daily intake of carbohydrates in females and $[20 \% 1 / 5]$ in males.

Numerical expressions used in the survey:

$18.3 \%$, menos de $1 / 5$ ('less than $1 / 5$ '), menos del $20 \%$ ('less than $20 \%$ '), menos de un quinto ('less than a fifth'), menos de veinte por ciento ('less than twenty per cent'), más de $1 / 4$ ('more than $1 / 4$ '), más del $25 \%$ ('more than $25 \%$ '), más de un cuarto ('more than a quarter'), más del veinte y cinco por ciento ('more than twentyfive per cent'), $27 \%$, casi el $50 \%$ ('almost 50\%'), menos de la mitad ('less than a half'), casi el cincuenta por ciento ('almost fifty per cent'), $48.6 \%$, menos de $1 / 2$ ('less than $1 / 2$ '), más de tres cuartos ('more than three quarters'), más del setenta y cinco por ciento ('more than seventy-five per cent'), $76.3 \%$, más de $3 / 4$ ('more than 3/4') and más del 75\% ('more than 75\%'). 